\title{
Calciuria and preeclampsia
}

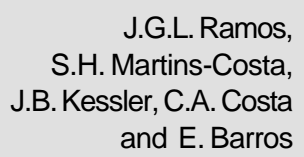

J.G.L. Ramos,

S.H. Martins-Costa,

J.B. Kessler, C.A. Costa

and E. Barros

Departamento de Ginecologia e Obstetrícia, Faculdade de Medicina, Universidade Federal do Rio Grande do Sul, Porto Alegre, RS, Brasil

Correspondence
J.G.L. Ramos
R. Ramiro Barcelos, 2350, r. 1125
90035-007 Porto Alegre, RS
Brasil
Fax: 55 (051) 333-1585
. . . . . . . . . . . . . . . . . . .

Received February 18, 1997 Accepted January 14, 1998

\section{Abstract}

Urinary calcium excretion has been reported to be diminished in preeclampsia. The objective of the present study was to determine urinary calcium excretion in pregnant patients with chronic arterial hypertension $(\mathrm{CAH})$ and preeclampsia $(\mathrm{PE})$, and in normotensive patients $(\mathrm{N})$. Forty-four pregnant patients (gestational age, 20-42 weeks; $18 \mathrm{CAH}, 17 \mathrm{PE}, 9 \mathrm{~N}$ ) were evaluated for calciuria, proteinuria, plasma uric acid and blood pressure. Patients with PE $(82 \pm 15.1 \mathrm{mg} /$ $24 \mathrm{~h})$ showed significantly lower calciuria $(\mathrm{P}<0.05)$ than the group with CAH $(147 \pm 24.9 \mathrm{mg} / 24 \mathrm{~h})$ and the $\mathrm{N}$ group $(317 \pm 86.0 \mathrm{mg} / 24 \mathrm{~h})$ $(\mathrm{P}<0.05$, Student $t$-test). Plasma uric acid was significantly higher in the PE group $(6.1 \pm 0.38 \mathrm{mg} / \mathrm{dl})$ than the $\mathrm{CAH}$ group $(5.0 \pm 0.33 \mathrm{mg} /$ $\mathrm{dl} ; \mathrm{P}<0.05)$, which also presented higher proteinuria levels, although the difference was not statistically significant. Diastolic and systolic blood pressure did not differ between the PE $(164 \pm 105 \mathrm{mmHg})$ and CAH (164 $\pm 107 \mathrm{mmHg}$ ) groups. Calciuria was significantly lower in the group with preeclampsia than in the group with chronic arterial hypertension. We conclude that calciuria can be a further factor for identifying preeclampsia.

\section{Introduction}

Hypertension occurs in 5 to $10 \%$ of our pregnant patients, corresponding to the major cause of maternal mortality in our midst as well as around the world (1). One way to reduce the impact of arterial hypertension on maternal mortality is to establish the correct diagnosis of preeclampsia, and to proceed with an early intervention when it is diagnosed (2). The classical clinical manifestation of preeclampsia is diagnosed when the pregnant patient presents high blood pressure levels $(>140 / 90 \mathrm{mmHg})$ after the 20th week of gestation (without a previous history of arterial hypertension) along with the presence of significant proteinuria ( $>300 \mathrm{mg}$ in $24 \mathrm{~h})(3)$.

Today these clinical signs are considered to be a late manifestation of a disease that has been present since the first trimester of gestation. Due to this "diagnostic delay", many tests have attempted to establish the diagnosis of preeclampsia as early as possible, often even before the patient presents arterial hypertension (4). Tests reported for the early diagnosis of preeclampsia are Doppler ultrasound assessment of maternal and fetal circulation (5-7), uric acid concentration (8), the supine pressure test (9-11), the angiotensin test (12), microalbuminuria (13), plasma fibronectin concentration (14), plasma antithrombin activity (15), calciuria and other tests, all of which are of debatable efficacy and practicality.

One of the difficulties of day-by-day obstetrical practice has been the differential diagnosis of chronic hypertension and pre- 
Figure 1 - Distribution of calciuria and proteinuria between groups. $\mathrm{PE}=$ Preeclampsia; $\mathrm{CAH}=$ chronic arterial hypertension; $\mathrm{N}$ = non-hypertensive controls.

Figure 2 - Distribution of calciuria and uric acid between groups. $\mathrm{PE}=$ Preeclampsia; $\mathrm{CAH}=$ chronic arterial hypertension; $\mathrm{N}=$ non-hypertensive controls.
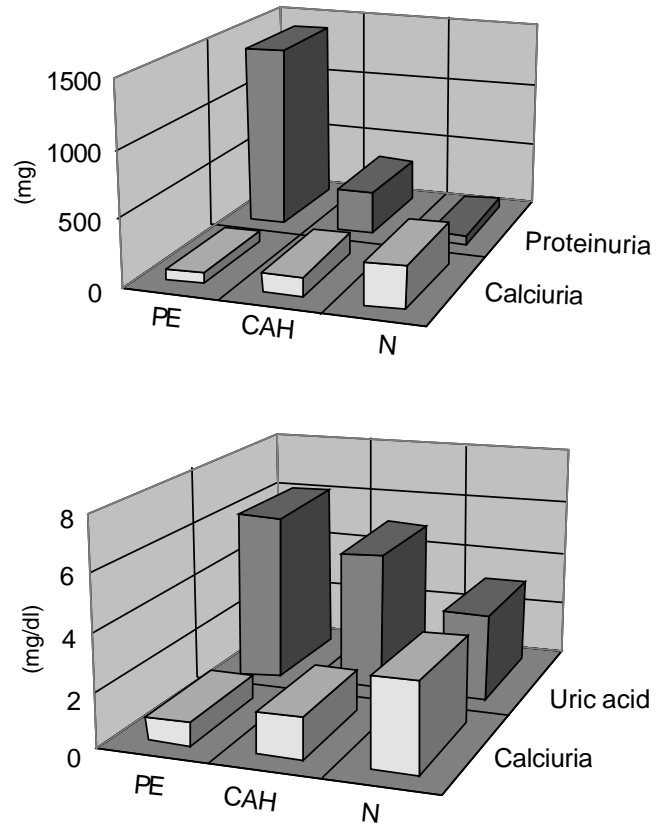

eclampsia, especially when the hypertensive patient presents proteinuria. Based on the observation that urinary calcium excretion is reduced in pregnant patients with preeclampsia, the authors determined the difference in calcium excretion between pregnant patients with the diagnosis of preeclampsia and pregnant patients with chronic arterial hypertension.

\section{Material and Methods}

We carried out an observational, transversal, controlled and prospective study in pregnant patients treated at the maternity clinic of the Hospital de Clínicas de Porto Alegre. Eligible patients had gestational ages from 20 to 42 weeks and arterial hypertension of 140/90 mmHg or higher. Patients who had established concomitant clinical disorders (diabetes mellitus, urinary infection, renal disorder, or epilepsy) as well as twin gestations were excluded from the study. All patients had normal serum creatinine $(<0.9 \mathrm{mg} / \mathrm{dl})$.

Patients were allocated to three groups, whose data were crossed and analyzed. Group I consisted of patients with a clinical diagno- sis of preeclampsia (PE) while group II consisted of patients with a diagnosis of chronic arterial hypertension $(\mathrm{CAH})$ without preeclampsia. The classification followed the guidelines of the American College of Gynecology and Obstetrics (3). Group III corresponded to a control group of non-hypertensive patients with gestational age from 20 to 42 weeks and with similar criteria for exclusion. The analyzed variables were 24 -h urinary calcium, $24-\mathrm{h}$ proteinuria, arterial pressure, and plasma uric acid.

Data were analyzed by the Student $t$ test for independent samples and the Fisher test with the level of significance set at $5 \%$. The results are reported as means \pm SEM. Data were stored and analyzed using the EPIINFO program. The study was approved by the Research and Ethics Committee of the Hospital de Clínicas de Porto Alegre.

\section{Results}

The average diastolic and systolic blood pressure levels did not differ significantly between group I (PE) and group II (CAH), although they were higher than in the control group, which did not have arterial hypertension. In group I, the average proteinuria ratio was higher than in group II, although not statistically significant.

The distribution of calciuria and proteinuria between the groups and their inverse relation are shown in Figure 1. Figure 2 shows the inverse relation between calciuria and uric acid.

Plasma uric acid was significantly higher $(6.1 \pm 0.38 \mathrm{mg} / \mathrm{dl})$ in group $\mathrm{I}(\mathrm{P}<0.05)$ than in group II $(5.0 \pm 0.33)$ and group III $(3.1 \pm$ $0.15)$. In group I (PE) the average calciuria ratio $(82 \pm 15.1 \mathrm{mg} / 24 \mathrm{~h})$ was significantly lower than the average $(147 \pm 24.9 \mathrm{mg} / 24 \mathrm{~h})$ for group II (CAH) (Table 1).

\section{Discussion}

Calciuria is a condition which has been 
studied in the detection of preeclampsia. Marya et al. (16) point out that urinary calcium excretion tends to increase in all pregnant patients, probably because of the increase in effective glomerular filtration rate. As also observed in the present study, Taufield et al. (17) found a significantly lower mean urinary calcium level in patients with preeclampsia and in hypertensive patients with preeclampsia (42 and $72 \mathrm{mg}$ in 24 $\mathrm{h}$, respectively), than in groups with chronic hypertension, and transitory hypertension and in normotensive patients $(223,248$, and 313 $\mathrm{mg} / 24 \mathrm{~h}$, respectively).

Huikeshoven and Zuijderhoudt (18) concluded that the measurement of urinary calcium excretion is of value for the study of pregnant patients with arterial hypertension, both in terms of 24-h excretion and in the calciuria/creatinuria ratio of a single urine sample.

Sanchez-Ramos et al. (19) suggest that patients with preeclampsia present a significantly lower total urinary calcium excretion $(129.7 \mathrm{mg} / 24 \mathrm{~h})$ than that observed for normotensive patients $(293.9 \mathrm{mg} / 24 \mathrm{~h})$ or for patients with pregnancy-induced hypertension $(232.2 \mathrm{mg} / 24 \mathrm{~h})(\mathrm{P}=0.0001)$. These data reflect a higher average than our data. Anai et al. (20) demonstrated that the average urinary calcium excretion is significantly lower in the group of patients with preeclampsia $(44.3 \mathrm{mg} / 24 \mathrm{~h})$ than in the group of patients with fetal growth retardation. Raniolo and Phillipou (21) determined that the calciuria/creatinine ratio was not significantly different between groups of normotensive pregnant patients $(0.52 \pm 0.32)$, patients with preeclampsia $(0.49 \pm 0.32)$ and patients with pregnancy-induced hyperten-
Table 1 - Calciuria and hypertension in gestation.

$\mathrm{PE}=$ Preeclampsia; $\mathrm{CAH}=$ chronic arterial hypertension; $\mathrm{N}=$ non-hypertensive controls. Data are reported as means \pm SEM. ${ }^{*} \mathrm{P}<0.05$ between groups I and II, II and III, and III and I. $+\mathrm{P}<0.01$ between groups III and I (Student $t$-test).

\begin{tabular}{lrcr}
\hline & $\mathrm{I}(\mathrm{PE} ; \mathrm{N}=17)$ & II $(\mathrm{CAH} ; \mathrm{N}=18)$ & III $(\mathrm{N} ; \mathrm{N}=9)$ \\
\hline Calciuria $(\mathrm{mg} / 24 \mathrm{~h})$ & $82 \pm 15.1^{*}$ & $147 \pm 24.9^{*}$ & $317 \pm 86.0^{*}$ \\
Proteinuria $(\mathrm{mg} / 24 \mathrm{~h})$ & $1395 \pm 654.5$ & $326 \pm 75.9^{*}$ & $63 \pm 18.8^{*}$ \\
Uric acid $(\mathrm{mg} / \mathrm{dl})$ & $6.1 \pm 0.38^{*}$ & $5.0 \pm 0.33^{*}$ & $3.1 \pm 0.15^{+}$ \\
Systolic $(\mathrm{mmHg})$ & $164 \pm 5.2$ & $164 \pm 4.2^{*}$ & $115 \pm 2.4^{+}$ \\
Diastolic $(\mathrm{mmHg})$ & $105 \pm 3.2$ & $107 \pm 3.0^{*}$ & $74 \pm 4.1^{+}$
\end{tabular}

sion $(0.57 \pm 0.40)$. The detection of calciuria is often contradictory, reflecting the need for new data.

Urinary calcium excretion has been already studied as a predictive test of preeclampsia. Sanchez-Ramos et al. (22) found a relative risk of 9.4 of predicting preeclampsia when the patient shows urinary calcium excretion lower than $195 \mathrm{mg} / 24 \mathrm{~h}$. Baker and Hackett (23) did not find significantly predictive values in the measurement of the albumin/creatinine and/or calcium/creatinine ratio in relation to the diagnosis of preeclampsia. Conde-Agudelo et al. (24) established that urinary calcium excretion produces contradictory and inconclusive findings for the predictive diagnosis of preeclampsia.

The present new results showed lower urinary calcium excretion in the group with preeclampsia than in the group with chronic arterial hypertension. A 24-h calciuria less than $100 \mathrm{mg} / 24 \mathrm{~h}$ may confirm a suspected preeclampsia. Thus, the measurement of calciuria could be used as a further test to differentiate between chronic arterial hypertensive disease and preeclampsia in pregnant patients. 


\section{References}

1. Martins-Costa $\mathrm{S}$, Hentschel H \& Ramos JG (1992). Causas de mortalidade materna no Hospital de Clínicas de Porto Alegre: análise de 10 anos. Revista Hospital de Clínicas de Porto Alegre, 12: 18-21.

2. Cunningham FG, MacDonald PC \& Gant NF (1989). Hypertensive disorders in pregnancy. In: Cunningham FG, MacDonald PC \& Gant NF (Editors), Williams Obstetrics. Prentice-Hall, Norwalk, 653-694.

3. National High Blood Pressure Education Program (1991). Working group report on high blood pressure in pregnancy. U.S. Department of Health and Human Services, 1-38.

4. O'Brien WF (1992). The prediction of preeclampsia. Clinical Obstetrics and Gynecology, 35: 351-364.

5. Steel SA, Pearce JM, McParkland $P$ \& Chamberlain GVP (1990). Early Doppler ultrasound screening in predicting of hypertensive disorders of pregnancy. Lancet, 335: 1548-1550.

6. McParkland P, Pearce JM \& Chamberlain GVP (1990). Doppler ultrasound and aspirin: recognition and prevention of pregnancy induced hypertension. Lancet, 335 : 1552-1553.

7. Jacobson SL, Imhof R \& Manning N (1990). The value of Doppler assessment of the uteroplacental circulation in predicting preeclampsia or intrauterine growth retardation. American Journal of Obstetrics and Gynecology, 162: 110-114.

8. Redman CW, Beilen LJ, Bonnar J \& Wilkinson RH (1976). Plasma-urate measurements in predicting fetal death in hypertensive pregnancy. Lancet, 1: 13701372.
9. Gant NF, Chand S, Worley RJ \& Daley GL (1974). A clinical test useful for predicting the development of acute hypertension in pregnancy. American Journal of Obstetrics and Gynecology, 120: 1-8.

10. Phelan JP, Everidge GL, Welder TL \& Newman C (1977). Is the supine test an adequate means of predicting acute hypertension in pregnancy? American Journal of Obstetrics and Gynecology, 128: 173-176.

11. Ramos JG \& Martins-Costa S (1989). Teste da pressão supina. Revista Hospital de Clínicas de Porto Alegre, 9: 125-127.

12. Gant NF, Daley GL, Chand S \& Worley RJ (1973). A study of angiotensin II pressor response throughout primigravid pregnancy. Journal of Clinical Investigation, 52: 2682-2689.

13. Rodriguez MH, Maskaka DI, Mestman J, Kumar D \& Rude R (1989). Calcium/creatinine ratio and microalbuminuria in the prediction of pre-eclampsia. American Journal of Obstetrics and Gynecology, 159: 1452-1457.

14. Erikson $\mathrm{HO}$, Hansen PK, Brocks $\mathrm{V}$ \& Jewsen BA (1987). Plasma fibronectin concentration in pre-eclampsia. Acta Obstetrica et Gynecologica Scandinavica, 66: 25-30.

15. Weiner CP \& Brandt J (1982). Plasma antithrombin III activity: an aid in the diagnosis of preeclampsia-eclampsia. American Journal of Obstetrics and Gynecology, 142: 275-277.

16. Marya RK, Rathee S \& Manrow M (1987). Urinary calcium excretion in pregnancy. Gynecologic and Obstetric Investigation, 23: 141-144.
17. Taufield PA, Ales KL, Resnick LM, Druzin ML, Gertner JM \& Laragh JH (1987). Hypocalciuria in preeclampsia. New England Journal of Medicine, 316: 715-718.

18. Huikeshoven FJ \& Zuijderhoudt FM (1990). Hypocalciuria in hypertensive disorder in pregnancy and how to measure it. European Journal of Obstetrics, Gynecology, and Reproductive Biology, 36: 8185.

19. Sanchez-Ramos L, Sandroni S, Andres FJ \& Kaunitz AM (1991). Calcium excretion in preeclampsia. Obstetrics and Gynecology, 77: 510-513.

20. Anai T, Hirota Y, Yoshimatsu J, Oga M \& Miyakawa I (1992). Hypocalciuria in women with preeclampsia. Nippon Sawka Fujinka Gakkai Zasshi, 44: 28-32.

21. Raniolo E \& Phillipou G (1991). Prediction of pregnancy-induced hypertension by means of the urinary calcium:creatinine ratio. Medical Journal of Australia, 158: 98-100.

22. Sanchez-Ramos L, Jones DC \& Cullen MT (1991). Urinary calcium as an early marker for preeclampsia. Obstetrics and Gynecology, 77: 685-688.

23. Baker PN \& Hackett GA (1994). The use of urinary albumine-creatinine ratios and calcium-creatinine ratios as screening tests for pregnancy-induced hypertension. Obstetrics and Gynecology, 83: 745749.

24. Conde-Agudelo A, Lede R \& Belizan $J$ (1994). Evaluation of methods used in the prediction of hypertensive disorders of pregnancy. Obstetrical and Gynecological Survey, 49: 210-222. 